\title{
Epidemiology and management of endometrial cancer: experience of International University Hospital Cheikh Khalifa and Mohammed VI Center for cancer treatment at University Hospital Ibn Rochd Casablanca, Morocco
}

Amal Bouziyane ( $\square$ amalbouziyane@gmail.com )

Mohammed VI University of Health Sciences: Universite Mohammed VI des Sciences de la Sante https://orcid.org/0000-0002-3627-7285

\section{Hicham Benaguida}

ibn rochd university hospital

Maryame Lamsisi

University Hassan II Casablanca: Universite Hassan II Casablanca

Ayoub Khoaja

Ibn Rochd University Hospital Center: Centre Hospitalier Universitaire Ibn Rochd

Samira Benayad

Ibn Rochd University Hospital Center: Centre Hospitalier Universitaire Ibn Rochd

Mohammed Ennachit

ibn rochd university hospital

Mohamed Elkarroumi

ibn rochd university hospital

Mustapha Benhessou

Ibn Rochd University Hospital Center: Centre Hospitalier Universitaire Ibn Rochd

Moulay Mustapha Ennaji

Hassan II University: Universite Hassan II Casablanca

Original Article

Keywords: Epidemiology, Endometrial adenocarcinoma, Hysterectomy, Pelvic lymph node dissection, Hyperoestrogenism

Posted Date: November 6th, 2020

DOI: https://doi.org/10.21203/rs.3.rs-100555/v1 
License: (c) (i) This work is licensed under a Creative Commons Attribution 4.0 International License. Read Full License 


\section{Abstract \\ Background}

Endometrial cancer is the fourth most common cancer in women in high-income countries and its incidence has increased over the past 20 to 30 years. In Morocco, the incidence is close to those found in developing countries, but it is lower than those found in Western countries. To determine some epidemiological aspects of endometrial cancer in Morocco, we conducted a prospective study over 43 months at the International University Hospital Cheikh Khalifa and the Mohammed VI Center for Cancer Treatment at the Ibn Rochd Casablanca University Hospital, Morocco. 93 cases of endometrial cancer were included.

\section{Results}

The average age was $64.36 .5 \%$ of our patients had early menarche. $17.2 \%$ had menstrual cycle abnormalities. The nulliparous patients represent 40.8囚. 3 patients in our series underwent medical hormone treatment. $46.2 \%$ of patients claimed to have taken oral contraception during their period of genital activity, $79.5 \rrbracket$ were obese, $62.3 \%$ of the patients are diabetic and $49.4 \%$ are known to be hypertensive. $9.6 \%$ of patients are on hormone therapy with Tamoxifen. Metrorrhagia is the first symptom encountered in $62.2 \%$ of cases. Ultrasound was performed on all of our first-line patients and pelvic MRI was the most relevant examination in the pre-therapeutic assessment of endometrial cancer. Endometrial adenocarcinoma of the endometriotic type $(81.72 \%)$ was the most prominent histological type. The therapeutic attitudes practiced were: Extended total colpohysterectomy for 17 patients. Total hysterectomy with bilateral salpingo-oophorectomy for 93 patients. Omentectomy was performed for 11 patients. 78 patients had undergone pelvic lymph node dissection, while 51 patients had undergone an associated lumbarortic dissection. $44.08 \bigotimes$ of cases were diagnosed at stage (IA) and 18.27 of cases at stage (III). At the time when we stopped our study, 42 patients had received radiotherapy as adjuvant treatment, ie $45.1 \%$ of cases.

\section{Conclusions}

Local and locoregional epidemiological studies should be multiplied to shed light on the interest of prevention by promoting a healthy lifestyle. Besides, genetic studies must be conducted to better understand the place of racial factors as risk factors for this cancer.

\section{Introduction}

Endometrial cancer is the fourth most common cancer in women in high-income countries such as the United States, Canada, and Australia where collectively more than 57,000 women are diagnosed each year [1], its incidence has increased over the past 20 to 30 years. In Europe, Endometrial cancer is the 
fourth most common cancer in women [2], and in the United States, 47.130 new cases of endometrial cancer were reported with 8,010 deaths in 2012 [3].

The incidence of endometrial cancer is low in developing countries. At the national level: In the Rabat registry, endometrial cancer is the 5th gynecological cancer, its frequency is $3.4 \%$ of gynecological cancers recorded in 2012 [4]. In the Casablanca registry, endometrial cancer is the 7th cancer in women, it represents $2.8 \%$ of all female cancers [5]. In the register of the Hassan II center in Fez, the proportion of endometrial cancer was approximately $6.7 \%$ of all gynecological cancers recorded between 2004 and 2007 [6]. The incidence of endometrial cancer in Morocco is close to that found in developing countries, but it is lower than that found in Western countries.

This work aims to study the epidemiological characteristics and the clinical therapeutic profile of a population of Moroccan patients with endometrial cancer in a university hospital setting in the city of Casablanca (International University Hospital Cheikh Khalifa and the Mohamed VI Center for the treatment of cancers at the Ibn Rochd University Hospital Center), for better prevention and therapeutic management of patients.

\section{Patients And Methods}

This prospective approach was undertaken to explore the underlying elements related to epidemiological characteristics, the clinical and the therapeutic profile of women with endometrial cancer at Cheikh Khalifa International University Hospital and the Mohamed VI Center for the treatment of cancers at the Ibn Rochd University Hospital Center, over 45 months, from January 1, 2017, to August 30, 2020.

Eligible participants were identified from the operating theater register, patient medical records, and pathology reports. An operating sheet was drawn up to extract the data necessary for our epidemiological study including the identity of the patient, the socio-demographic data, the circumstances of the discovery of the disease, the initial clinical examination, the results of the examinations complementary, the type of surgical and adjuvant treatment and the anatomopathological characteristics of the surgical specimens.

Women were eligible to participate if they had an endometrial cancer diagnosis and were aged between 18 and 85 years and treated within these structures. All the 93 identified patients consented to use the data in their charts in this study while respecting their anonymity.

\section{Results And Discussion}

\section{Risk factors for endometrial cancer}

Endometrial carcinoma occurs most commonly in postmenopausal women, in more than $75 \%$ of cases [7]. It is divided into two distinct types of cancer: type I cancer, the most frequent, developed in a context of hyperestrogenism and on lesions precursors of endometrial glandular hyperplasia, corresponds to an 
endometrioid adenocarcinoma, it is good. prognosis [8]. While type II cancer, less common, develops on lesions of Intra mucous carcinoma in a context of atrophic mucosa, its histological type is more aggressive either of serous adenocarcinoma type or with clear cells with a poorer prognosis.[8]. Hyperestrogenism can be of exogenous origin (medical hormonal treatment, Tamoxifene ${ }^{\circledR}$ ) or endogenous origin (polycystic ovary syndrome, ovarian tumor, obesity, etc.). Other risk factors are high blood pressure, hyperlipidemia, and nulliparity, a genetic predisposition like Lynch syndrome can also promote this type of cancer.[9].

\subsection{Age}

Age is the most important risk factor for endometrial cancers which are most common, the prevalence gradually increases from the premenopausal stage, and maximum risk is seen in postmenopausal women. The risk decreases after 70 years of age [10]. However, $10 \%$ to $15 \%$ of cancers can occur in premenopausal patients and $2 \%$ to $5 \%$ of these will be under 40 years of age [11]. Up to a third of these young patients will also present with synchronous primary ovarian cancer or metastases at the time of diagnosis.[11] Philippe and Charpin place the average age between 59-60 years [12]. Other studies reveal an average age of 57.5 years, and $2 \%$ of cases before 40 , including one diagnosed at the age of 12 [13].

In the series of Agostini et al., The mean age of the patients was 53.4 years (range: $45-76$ years) [14].

In this study, we find that our results are in line with those of the literature with extreme ages between 49 and 82 years, the average age of 64 years, 16.13 patient of patients are in peri-menopause (Age between 45 and 55 years) and $83.87 \%$ are postmenopausal women over 55 years old (Figure 1).

\subsection{Racial and regional factors}

The incidence rate is higher in the white population compared to the black or Asian populations. However, the death rate among the black population is higher than the other two. Furthermore, there are also regional variations within racial groups, the incidence among black and Asian women living in the United States is much higher than that of their counterparts in other countries (14.15).

There are regions with a high incidence between 8 and $10 \otimes$ such as the United States, Canada, Australia, and Western Europe, and regions with a low incidence between 2 and $4 \otimes$ such as Africa, Central America, South America, and Asia [17]. This racial variation suggests that there are important genetic and environmental factors that influence the development of endometrial cancer. In our series, $83.88 \%$ of our patients are white, $12.9 \%$ are black and $3.22 \%$ are mixed race (Table 1 )

\subsection{Hormonal factors}

Endometrial adenocarcinoma is considered a hormone-dependent disease. The risk factors for endometrial cancer are generally linked to relative hyperestrogenism: early menarche, late menopause, 
chronic anovulation, postmenopausal obesity, synthetic estrogen intake, and also treatment with Tamoxifen [8] (Table 2).

\subsubsection{Menarche, cycle abnormalities, parity:}

Most studies have found that early menarche and late menopause are positively associated with the risk of endometrial adenocarcinoma [15], both of these factors result in a long duration of estrogen exposure during which anovulatory cycles are common. The menopause before age 53 years doubles the risk of endometrial cancer (16). An association with long or irregular menstrual cycles as well as nulliparity has also been reported as a risk factor [18]. Pregnancy appears to be a protective factor for endometrial adenocarcinoma. The risk of cancer is 0.9 (95\% Cl: 0.7-1.1), 0.8 (95\% Cl: $0.6-1.0)$, and 0.7 (95\% Cl: 0,50.8 ) for patients who have had 1, 2 or 3 or more children, respectively. Some studies have shown that nulliparity and infertility are risk factors for endometrial adenocarcinoma and other studies show that nulliparity continues to be a factor of poor prognosis [19]. In our series, $36.5 \%$ of our patients had early menarche, $17.2 \%$ had menstrual cycle abnormalities and $40.8 \%$ were nulliparous (Table 2 ).

\subsubsection{Medical hormone therapy}

In the late 1960s and early 1970s, unopposed estrogen therapy was recognized as a pathogenic factor in endometrial adenocarcinoma, associated with an incidence multiplied by 8 according to Ziel et al. [20]. This risk increases with the dose and the duration of use. When a woman uses systemic estrogen therapy without progestin for 1 year, it was found that endometrial hyperplasia developed in $20-50 \%$ of women [21]. The highest risk is noted in women using high doses for 10 years or more and remains high 5 to 10 years after stopping estrogen [22]. It appears that most regimens of combined estrogen-progestin postmenopausal hormone therapy are not going to increase the chances of endometrial carcinoma. Women's Health Initiative randomized trial had illustrated this when they compared continuous estrogenprogestin therapy with placebo [23].

The anti-estrogenic effect of progesterone and progestins is confirmed in epidemiological surveys by the reduction in the incidence of cancer in women receiving hormonal treatment when it combines a progestogen with estrogen [24]. In terms of benefit-risk analysis, the argument for prescribing a medical hormone therapy (MHT) for these young women is mainly to improve their quality of life as for avoiding the brutal consequences of surgical menopause such as hot flashes, vaginal dryness, and disturbed sexuality. For those women who have had a hysterectomy, the MHT contains estrogen alone, should be given at the minimum dose that improves the quality of life. Since, still according to the RPC (recommendations for clinical practices), the indications and contraindications after 50 years are the same as in the general population, it will then have to be stopped: we could advise to do it gradually, to avoid a sudden resumption of hot flashes [25]. Three of our patients underwent menopause medical hormone therapy. 


\subsubsection{Hormonal contraception}

All the literature shows a decrease in the incidence of endometrial cancer under combined oral contraception. The use of combined estrogen-progestin oral contraceptives decreases the risk of endometrial carcinoma by $30 \%$ [24]. Studies have found that progestin-only contraceptives (e.g., depot medroxyprogesterone acetate, progestin implants, progestin-releasing intrauterine devices) provide a protective effect against the development of endometrial neoplasia (23). The relative risk increases to 0.4 at 5 years after the use of combined oral contraception [26]. Therefore, it is correlated with the duration of use: compared to non-users, the risk is $77 \%$ after one year, $54 \%$ after four years, and $30 \%$ after 12 years. Protection decreases after stopping the pill but persists in part for 3 to 10 years, even 20 years, according to studies [27]. In our study, out of 93 patients, 43 claimed to have taken hormonal contraception during their period of genital activity (Table 2).

\subsubsection{Tamoxifen}

The risk is even greater if the patient has received Tamoxifen as adjuvant therapy [28]. The median time to onset of endometrial adenocarcinoma is 3.5 and 4 years [29]. The first cases of endometrial adenocarcinoma to appear with Tamoxifen were reported in 1985 by Killackey et al. [30]. Since this association has been studied and it is now accepted that treatment with Tamoxifen increases the risk of endometrial adenocarcinoma by a factor of the order of 2 to 3 in postmenopausal women. whereas the risk in premenopausal women is unproven to date [31]. The American College of Obstetricians and Gynecologists does not recommend routine screening for endometrial carcinoma in women on tamoxifen but advises that women be counseled about the risks associated with tamoxifen and should be monitored closely for symptoms of endometrial hyperplasia or carcinoma and undergo evaluation if symptoms of endometrial carcinoma are present [20]. In our series, the notion of taking Tamoxifen was found in 9 patients.

\subsection{Diabetes, High Blood Pressure, and Obesity}

Patients with hypertension and diabetes have a risk multiplied by 3 . Diabetes does not seem to be when isolated, a risk factor, and hypertension is classically found in this context [32]. Obesity is a prominent risk factor for the development of endometrial cancer that increases proportionally with BMI [33]. In our series, $62.3 \otimes$ of our patients are diabetic, $79.5 \otimes$ are obese and $49.4 \%$ are hypertensive (Table 3 ).

\subsection{Family history and background}

The relative risk of endometrial cancer is 1.5 with a similar family history (31). A family history of endometrial cancer and colorectal cancer has a high risk for the disease. They develop endometrial cancer at an early age [35]. According to the study by Lécuru et al. The age at the time of diagnosis is 
earlier. It is between 46 and 48 years old [36]. 15\% of cancers are diagnosed before the age of 40 years, $57 \%$ before age 50 years, and $98 \%$ before age 65 years. There is no notable characteristic, neither histological nor prognostic, of endometrial adenocarcinomas occurring in an HNPCC context compared to sporadic ones. In the context of HNPCC syndrome, there is no indication for routine prophylactic surgery. However, a non-conservative total hysterectomy can be discussed during abdominopelvic surgery. Personal history of breast cancer increases the risk of serous-like endometrial cancer [36]. In our series, we find a personal or family neoplastic history in 17 patients: 12 patients with breast cancer, 9 of whom were treated with Tamoxifen $(\mathrm{RH}+), 2$ patients followed for adenocarcinoma of the colon, and 3 patients whose mothers had endometrial cancer.

\subsection{Tobacco and Alcohol}

In several studies, smoking has been found to have a protective effect on endometrial carcinoma [37]. This phenomenon is explained by the anti-estrogenic action of tobacco, the mechanism suggested for this effect is that smoking stimulates the hepatic metabolism of estrogens, leading to the lowering of estrogen which eventually leads to a reduction of incidence of endometrial abnormalities. Two of our patients are smokers [38].

Excessive alcohol consumption leads to an increase in estrogen, prompting an investigation into the effect of alcohol on the risk of endometrial adenocarcinoma. Results showed no association or protective effect $[38,39]$. None of our patients drink alcohol.

\section{Anatomopathological profile}

The pathological diagnosis of endometrial cancers was made, according to the criteria of the histological classification of the World Health Organization, preoperatively, when possible, on the examination of a biopsy sample obtained by Pipelle de Corner bone, biopsy curettage, hysteroscopic sampling or another type of sample (cervical-uterine smear, a biopsy of a vaginal mass, etc.) and postoperatively by examination of the operative part. In several studies, the most common histological diagnosis is endometrioid adenocarcinoma [40]. Malik et al reported a sensitivity of $83.3 \%$ and a specificity of $95.4 \%$ using an insemination cannula [41]. Hemalatha et al. found that the diagnostic accuracy was higher in aspiration cytology than in dilation and curettage since two cases of endometrial hyperplasia were missed during dilation and curettage, but were diagnosed by suction cytology and confirmed by hysterectomy. The correlation of aspiration cytology with dilation and curettage was $94 \%$. Roger et al reported $98 \%$ and Maurice et al reported $93.75 \%$ correlation of cytology with dilation and curettage ratios [42].

In the series by Groff et al. The endometrial biopsy was performed on $66.3 \%$ of patients and it allowed the preoperative diagnosis of endometrial adenocarcinoma to be made in only $36.6 \%$ of cases [43]. The extemporaneous examination of the hysterectomy specimen is not recommended, as the specificity is 
low on myometrial infiltration and the histological grade.[44]. Analysis of the operative specimen after paraffin embedding allows in $25 \%$ of cases a grade change between the biopsy and the operative specimen and in $5 \%$ of cases a histological change and specifies the FIGO stage, myometrial invasion, the macroscopic size of the tumor, the depth of the invasion, the lymph node invasion, the presence of vascular emboli, the extension to the uterine cervix and the ectopic extension. In our series, all of our patients underwent an endometrial biopsy which made it possible to diagnose endometrial adenocarcinoma in $97.86 \%$ of cases and $2.14 \%$ of carcinosarcoma (figure 2; figure 3 and figure 4 ) (Table 4).

\section{Clinical signs}

\subsection{Metrorrhagia}

The early detection rate of EC is thought secondary to the presence of warning symptoms, such as postmenopausal bleeding that prompt evaluation of these patients. In our series, metrorrhagia is the first symptom encountered in all cases, they are of low or medium abundance. They are often isolated and constitute the only circumstance of discovery. It's found in $62.2 \%$ of our patients. In young women, it can also be discovered during a hysteroscopy performed as part of an infertility assessment or during the removal of an endocavitary polyp. In the study by Rossard et al. metrorrhagia accounts for $77 \%$ of symptoms, in a study by k. Nouni at the National Institute of Oncology in Rabat (2005-2007), metrorrhagia is found in $89 \%$ of patients $[45,46]$.

\subsection{Pelvic pain}

They are often associated with metrorrhagia. In our series, they are found in one way in $29 \%$ of cases. This frequency is greater than that of the series by Rossard et al. (2.9\%) [45]. Low et al. surveyed 911 women in the United Kingdom on the presence of gynecological cancer symptoms in the preceding 3 months, and found that $44 \%$ of respondents experienced at least one of the surveyed symptoms. The most common symptoms reported were abdominal, back, or pelvic pain and increased abdominal size, and $21 \%$ of those surveyed reported three or more symptoms [47].

\subsection{Leucorrhoea}

Abnormal vaginal discharge was also strongly associated with EC and reported in $11.8 \%$ of our patients. They can be isolated or associated with bleeding and pelvic pain. In the series by Rossard et al. Abnormal vaginal discharge represents only $3.7 \%$ of cases. In Nouni's series, leucorrhoea represents $29 \%[45,46]$.

\subsection{Other clinical signs:}


Alteration of general condition, urinary, and digestive signs are encountered in $5.37 \%, 8.6 \%$, and $7.7 \%$ of cases, respectively. These signs are often indicative of advanced forms, it is often a high grade or nonendometroid cancer (Table 5).

\section{Paraclinical examinations}

\subsection{For diagnostic proposes}

\subsubsection{Pelvic and endovaginally ultrasound:}

Ultrasound was performed in all our patients, it was an endovaginal and suprapubic ultrasound, it showed the presence of a uterine tumor in 82 patients and endometrial hypertrophy in 11 patients. Ultrasound plays a fundamental role in the diagnosis of endometrial cancer, to limit the invasive examinations carried out in patients with post-menopausal bleeding since $80 \%$ of curettages performed highlight a benign pathology.[13]. This examination makes it possible to estimate the myometrial penetration and to verify the integrity of the appendages. [48]. If the morphological criteria are associated with the morphometric criteria, the sensitivity of the ultrasound examination in the diagnosis of endometrial adenocarcinoma goes from 94 to $97 \%$ with a specificity of 45 to $65 \%$ for a limit thickness set at $5 \mathrm{~mm}[49]$.

The performance of endovaginal ultrasound in the assessment of the extension of endometrial adenocarcinoma varies in the literature. Indeed, the ultrasound examination proves to be very effective for the diagnosis of myometrial invasion, it is much less when it comes to proposing a precise "staging". Its sensitivity then goes from $94 \%$ to $66 \%[13,50]$. Several studies already reported in the literature on the performance of endovaginal ultrasound in the diagnosis of deep myometrial extension have shown significant reliability with figures comparable to those of MRI $[20,51,52]$.

\subsubsection{Hysteroscopic endometrial biopsy}

86 of our patients underwent this examination in the operating room under anesthesia and it made it possible to make the diagnosis of endometrial cancer in $92.4 \%$ of cases. 7 cases are patients referred from other structures following a diagnosis made on a hysterectomy specimen without prior histological proof. Curettage after dilation has long been considered the gold standard for removing endometrial mucosa. A satisfactory sample is obtained in 80 to $95 \%$ of cases [49]. Curettage after dilation, which requires general anesthesia, should be reserved for cases where sufficient material cannot be obtained on an outpatient basis, due to cervical stenosis for example, or when it is performed for therapeutic purposes at the same time as diagnostic [53]. 


\subsection{Assessment of extension}

\subsubsection{Magnetic resonance imaging (MRI)}

This examination was performed on all of our patients (Figure 5). The results were as follows: The Endometrial thickness had an average value was $12 \mathrm{~mm}$ with extremes ranging from 06 to $28 \mathrm{~mm}$, the invasion of the myometrium was greater than $50 \%$ of the total thickness of the myometrium in 28 cases, the cervical involvement was objectified in 09 patients, the Ectopic extensionwas objectified in 32 cases: 7 cases of endometrial cancer exceeding the uterine serosa, 4 cases with bladder involvement, 3 cases with intestinal involvement and 8 cases with parametrial involvement and 2 cases with ovarian involvement, and the suspicion of pelvic and / or lumboaortic lymph node involvement was objectified in 23 cases.

Abdominopelvic MRI is the most relevant examination in the pre-therapeutic evaluation of endometrial cancer [54]. This examination allows the realization of a locoregional extension assessment (penetration of the myometrium, lymph node invasion, cervical extension) [55]. The lesion will manifest as a localized or diffuse endometrial thickening, more or less heterogeneous. It appears in hyper signal in T2 but the signal is hypointense compared to the endometrium [56]. The invasion of the cervix will be evoked in the event of an abnormality of the signal of the tumor at the level of the cervical canal or the stroma or in the presence of the existence of an enlargement of the cervical canal linked to the tumor [57].

If ultrasound is the first examination to be requested for diagnosis, MRI is the imaging technique to recommend in the assessment of extension of endometrial adenocarcinomas: certain authors such as Del Maschio et al. consider that the results between the two methods are similar, but others such as Yamashita et al. using both T2 and dynamic gradient-echo get better results (43.48). Kinkel recommended the use of first-line MRI only in cases where there is a high histologic grade tumor because of the high risk of lymph node involvement.[50]; or else in the face of clinical suspicion of extension to the cervix; or as part of a multifactorial assessment (myometrium, cervix, and lymph node status).

\section{Therapeutic conduct}

\subsection{Surgical treatment}

In our series, surgical treatment has always represented the cornerstone of treatment, all patients have undergone surgery. The main goal of surgery is therapeutic by the removal of the tumor. Also, uterine resection allows the determination of prognostic factors and hence decisions on the adjuvant treatment (Figure 6 and Figure 7). For early-stage EC, a total extra fascial hysterectomy with bilateral salpingooophorectomy was performed. The decision to perform a lymphadenectomy depends on the local practice and the risk of nodal disease (determined a priori by the preoperative or intraoperative data). 
This first objective of surgery may be limited to a simple hysterectomy and the removal of the ovaries; however, its second goal requires a much more extensive intervention that involves pelvic washing, omentum biopsy or complete omentectomy, pelvic lymphadenectomy, and para-aortic lymphadenectomy [58].

The diagnostic role of lymphadenectomy is to define the extent of disease, thus targeting adjuvant therapy and identifying patients who may not need postsurgical treatment. The potential therapeutic role is to eradicate the existing disease in the nodal tissue. However, it is still debated and the treatment of endometrial cancer varies largely across practitioners. In the UK, the MRC ASTEC trial, which randomized 1400 women undergoing surgery for presumed Stage I endometrial cancer to pelvic lymphadenectomy or no lymphadenectomy, showed no therapeutic benefit [59]. Performing cytology and complete peritoneal exploration also provide prognostic information, the results of which are necessary for classification in the FIGO system. The indication for systematic omentectomy is reserved for the treatment of serous papillary forms (53) (Table 6).

The staging of endometrial cancer has still, since the publication of Creasman et al., Been based on surgical status (54.55). Old series, such as that of Lewis et al. In the 1970s, at the time justified this almost systematic attitude by a significant decrease in myometrial invasion after irradiation (56). In 1987, the publication of the results of the study GOG 33 (Gynecologic Oncology Group Study) shed new light on the management of endometrial cancers. This American study, published by Creasman et al. aimed to correlate the characteristics of endometrial adenocarcinomas with their ectopic extension (54). The description of such uterine histological factors should make it possible to better orient complementary treatments. This work justified, in 1988, the modification and establishment of a new method of classifying endometrial adenocarcinomas and placed the surgical approach in the first line (57).

In $25 \%$ of cases, a change in grade between the curettage and the operative specimen may appear and in $5 \%$ of cases a change in histological type. If high-risk factors are found on the hysterectomy specimen, rework of lymph node and peritoneal staging, preferably laparoscopic, is recommended. The prognosis is related to the stage, the depth of myometrial infiltration, the histologic grade, and the presence of metastatic lymph nodes (58).

A recent analysis of patients with a preoperative diagnosis of grade 1 disease found that $4 \%$ of patients had lymph node metastases, $10 \%$ had the disease beyond the uterus, and $25 \%$ had other characteristics that exposed them to high risks that could influence the planning of subsequent adjuvant therapy (59). Given these large differences, preoperative tumor grades cannot be used to reliably stratify the risk of the presence of ectopic metastases and determine the need for surgical staging (60).

\subsection{Adjuvant treatment}

\subsubsection{Radiotherapy}


At the time when we stopped our study, 42 patients ( $45.1 \%$ of cases) had received radiotherapy as adjuvant treatment. The treatment of early-stage endometrial cancer is based on surgical management including total hysterectomy and bilateral salpingo-oopharectomy. Depending on clinical situations and prognostic factors, lymph nodes evaluation by pelvic and lumbar-aortic lymph nodes dissection will be performed.

For patients with a uterine limited disease with intermediate- and high-risk factor 4 randomized trials and a Cochrane meta-analysis have evaluated the role of radiation therapy (EBRT) (X) concluding that radiation treatment reduces the risk of locoregional recurrence without increasing overall survival [60]. For patients who present, at postoperative reassessment, a tumor confined to the body of the uterus with criteria of low risk of recurrence, the reference attitude is simple monitoring. For patients at intermediate risk or high risk of recurrence, several prospective randomized trials, meta-analyses, and large retrospective series have made it possible to support the adjuvant treatment proposals, according to the tumor histopathological prognostic factors, leading to recommendations. under the aegis of the European Society for Medical Oncology (ESMO) [61]. Any operable patient must be operated and external radiotherapy will be delivered after the surgery in the following cases:

- Stage I high risk (IB grade 3, IB with lymphatic emboli, or histological type 2) with optional brachytherapy to reduce vaginal recurrence.

- Stage Il: surgery followed by brachytherapy, radiotherapy may be offered

- Stage III: chemotherapy and external radiotherapy.

- IVA internship: external radiotherapy followed by brachytherapy

Radiotherapy is most often used in addition to surgery but can be exclusive, in inoperable patients or patients with advanced tumors. Adapted to prognostic factors, it reduces the rate of locoregional tumor recurrence [62]. External beam radiation therapy for endometrial adenocarcinoma is usually done postoperatively. It may be indicated before surgery for tumors with an unfavorable prognosis, or only in stage II tumors to sterilize subclinical lymph node metastases and thus to abstain from dissection [63]. In endometrial adenocarcinomas, it targets a selected population carrying sufficient risk indicators to predict the risk of pelvic relapse greater than $10 \%$. Pelvic radiotherapy aims to reduce recurrence in the irradiated area [64].

Different target volumes can be defined according to the therapeutic strategy and therefore to the place of external radiotherapy (postoperative, exclusive, preoperative, etc.) and according to the extent of the disease. Three types of volumes will be described: pelvic, lumbar-aortic, and abdominal. Postoperative brachytherapy uses cesium 137 for low endocardial flow brachytherapy and iridium for high dose rate or pulsed flow brachytherapy [62]. Preoperative brachytherapy is endocavitary, uterovaginal, and is similar in all respects to preoperative brachytherapy for cervical cancer. It allows better cervicovaginal irradiation and proximal parameters by minimizing the dose to critical organs (sigmoid, small loops, and bladder) due to the interposition of the uterus. Its interest remains in stage II tumors with macroscopic involvement 
of the uterine cervix. The target volume: includes the upper third of the vagina, the cervix, parameters, and the uterine cavity if possible.

\subsubsection{Chemotherapy:}

Management of endometrial cancer has become more complex during the past 10 years for several reasons: changes in histological classification (type 1 vs. type 2) have affected surgical management, adjuvant therapy strategies deeply modified based on data from randomized trials and indications and modalities of lymphadenectomy have changed, even if the therapeutic or simply prognostic role of lymphadenectomy remains to be defined. A meta-analysis on the role of adjuvant chemotherapy in highrisk endometrial cancer including 9 trials and 131,326 patients reported that adjuvant chemotherapy significantly increases overall survival (HR 0.74) and progression-free survival (HR 0.75) and reduce the risk of distant metastasis (HR 0.79) [65]. In our series, 27 patients received chemotherapy courses based on Carboplastine + paclitaxel. Traditionally, until the 1990s, chemotherapy was reserved for patients with metastatic cancer. The demonstration of high metastatic risk in certain subgroups and the positive results of chemotherapy in the advanced forms have led to the gradual introduction of chemotherapy into the treatment protocols of patients with cancer at high risk of recurrence [66]. The place of adjuvant chemotherapy, in more limited stages, is unclear and uncertain. It could be justified in the form of a high risk of recurrence. The Doxorubicin-Cisplatin combination was the cornerstone for randomized trials. There is an increasing trend for paclitaxel. In new trials, the Carboplatin-Taxol combination is frequently found [67]. The European Organization for Research and Treatment of Cancer (EORTC) conducted a randomized trial evaluating adjuvant chemotherapy, either before or after postoperative external irradiation. The 5-year disease-free survival rate was improved from 75 to $82 \%$ with the addition of chemotherapy [66].

The results of these various trials have shown the potential benefit of chemotherapy in reducing the risk of remote metastases in forms with a high risk of recurrence. However, the use of chemotherapy alone exposes patients to a higher risk of locoregional recurrence. Mundt et al. [80] reported a $40 \%$ risk rate of local recurrence at three years in patients who received only chemotherapy after surgery, and in $31 \%$ the pelvis was the first or only site of recurrence. . These experiments have led to the consideration of combining chemotherapy with radiotherapy, either concomitantly or sequentially.

\section{Conclusion}

As for the epidemiological data on risk factors, the results of our study match those of the literature; including classic risk factors such as age, the area of hyperestrogenism, obesity, sedentary lifestyle, diabetes, and arterial hypertension. Local and locoregional epidemiological studies should be multiplied to shed light on the interest of prevention by promoting a healthy lifestyle: fight against sedentary lifestyle, screening, and monitoring of cardiovascular diseases and diabetes, surveillance regular use of patients on Tamoxifen but also through genetic counseling in populations at risk. Besides, genetic 
studies must be conducted to better understand the place of racial factors as risk factors for this cancer. Endometrial cancer is cancer that is treated with surgery. Radiotherapy is the main adjuvant treatment. This cancer is generally of good prognosis with a 5-year survival which reaches $70 \%$, all stages combined, for our patients, the collection of data on survival is in progress and subject to a later study.

\section{Abbreviations}

ADK

Adenocarcinoma

BMI

Body Mass Index

HBP

High Blood Pressure

MRI

Magnetic resonance imaging

\section{Declarations}

\section{Ethics approval and Consent to participate}

This study is approved by local Ethical committee. All patients consented to the participation of this study.

\section{Consent for publication}

The authors consent for the publication of the data presented in the present article

\section{Availability of data and material}

All data generated or analyzed during this study are included in this published article

\section{Competing interest}

The authors declare that they have no competing interests

\section{Funding}

No funding was received to assist with the preparation of this manuscript. 


\section{Authors contribution}

AB: Study design, Data collection and interpretation, writing and editing; HB: Data collection and interpretation, Manuscript writing and editing; ML: Data interpretation, Manuscript writing and editing; AK and S B performed the histological examination; MEN: Providing resources, manuscript editing; MEL: Providing resources, manuscript editing; MB: study design, Data interpretation, writing and editing; MME: Supervision. All authors read and approved the final manuscript.

\section{Acknowledgments}

The authors would like to thank all the participating patients and the medical and paramedical staff at the both the hospitals where this study has been held, for all their efforts to support us during this study.

\section{References}

1. Latest world cancer statistics - GLOBOCAN 2012: Estimated Cancer Incidence, Mortality and Prevalence Worldwide in 2012 - IARC. https://www.iarc.fr/news-events/latest-world-cancerstatistics-globocan-2012-estimated-cancer-incidence-mortality-and-prevalence-worldwide-in-2012/. Accessed 3 Oct 2020

2. Ferlay J, Steliarova-Foucher E, Lortet-Tieulent J, et al (2013) Cancer incidence and mortality patterns in Europe: Estimates for 40 countries in 2012. Eur J Cancer 49:1374-1403. https://doi.org/10.1016/j.ejca.2012.12.027

3. Siegel R, Naishadham D, Jemal A (2012) Cancer statistics, 2012. CA Cancer J Clin 62:10-29. https://doi.org/10.3322/caac.20138

4. (2012) CANCER INCIDENCE RATE IN RABAT Q

5. (2008) REGISTRE DES CANCERS-de la Région du Grand Casablanca pour la période

6. Chbani L, El Fatemi H, Znati K, et al (2009) Épidémiolgie des cancers au CHU Hassan II, Fès, 20042007. Rev Epidemiol Sante Publique 57:S19. https://doi.org/10.1016/j.respe.2009.02.066

7. Albertini AF, Devouassoux-Shisheboran M, Genestie C (2012) Anatomopathologie des cancers de l'endomètre. Bull. Cancer 99:7-12

8. Gupta D (2017) Clinical behavior and treatment of endometrial cancer. In: Advances in Experimental Medicine and Biology. Springer New York LLC, pp 47-74

9. Morice P, Leary A, Creutzberg C, et al (2016) Endometrial cancer. In: The Lancet. Lancet Publishing Group, pp 1094-1108

10. Siegel R, Ward E, Brawley O, Jemal A (2011) Cancer statistics, 2011. CA Cancer J Clin 61:212-236. https://doi.org/10.3322/caac.20121

11. Renaud MC, Plante M (2001) Medical Treatment of Endometrial Carcinoma for the Premenopausal Woman Wanting to Preserve her Ability to Have Children. J SOGC 23:213-219. 
https://doi.org/10.1016/s0849-5831(16)30168-9

12. Philippe E, Charpin C (2015) Precancerous Lesions and Carcinomas of the Endometrium. In: Endometrial Cancers. S. Karger AG, pp 45-51

13. Collinet P, Poncelet É, Vinatier D (2008) Cancer de l'endomètre. J Gynecol Obstet Biol la Reprod 37:. https://doi.org/10.1016/S0368-2315(08)75574-1

14. Agostini A, Schaeffer V, Cravello L, et al (2003) Place de l'hystéroscopie dans le diagnostic et la prise en charge des hyperplasies atypiques de l'endomètre. Gynécologie Obs Fertil 31:355-358. https://doi.org/10.1016/S1297-9589(03)00065-1

15. Parazzini F, Negri E, La Vecchia C, et al (1998) Role of reproductive factors on the risk of endometrial cancer. Int J Cancer 76:784-786. https://doi.org/10.1002/(SICI)10970215(19980610)76:6<784::AID-IJC2>3.0.C0;2-U

16. Creasman WT, Odicino F, Maisonneuve P, et al (2001) Carcinoma of the corpus uteri. J Epidemiol Biostat 6:45-86

17. Kenemans P, Verstraeten RA (2005) Sex hormones, anti-hormones and adenocarcinoma of the endometrium. Int Congr Ser 1279:154-157. https://doi.org/10.1016/j.ics.2005.01.013

18. Xu WH, Xiang YB, Ruan ZX, et al (2004) Menstrual and reproductive factors and endometrial cancer risk: Results from a population-based case-control study in urban shanghai. Int J Cancer 108:613619. https://doi.org/10.1002/ijc.11598

19. GIUDICE LC, LAMSON G, ROSENFELD RG, IRWIN JC (1991) Insulin-like Growth Factor-II (IGF-II) and IGF Binding Proteins in Human Endometrium. Ann N Y Acad Sci 626:295-307. https://doi.org/10.1111/j.1749-6632.1991.tb37924.x

20. Ziel HK, Finkle WD (1975) Increased Risk of Endometrial Carcinoma among Users of Conjugated Estrogens. N Engl J Med 293:1167-1170. https://doi.org/10.1056/NEJM197512042932303

21. Furness S, Roberts H, Marjoribanks J, Lethaby A (2012) Hormone therapy in postmenopausal women and risk of endometrial hyperplasia. Cochrane Database Syst Rev. https://doi.org/10.1002/14651858.cd000402.pub4

22. Schlesselman JJ (1997) Risk of endometrial cancer in relation to use of combined oral contraceptives. A practitioner's guide to meta-analysis. Hum. Reprod. 12:1851-1863

23. Vessey MP, Painter R (1995) Endometrial and ovarian cancer and oral contraceptives - findings in a large cohort study. Br J Cancer 71:1340-1342. https://doi.org/10.1038/bjc. 1995.260

24. Sherman ME, Sturgeon S, Brinton LA, et al (1997) Risk factors and hormone levels in patients with serous and endometrioid uterine carcinomas. Mod Pathol 10:963-968

25. Quereux C, Gabriel R (2003) Non contraceptive benefits of oral contraception. Gynecol. Obstet. Fertil. 31:1047-1051

26. Shu X -O, Brinton LA, Zheng W, et al (1991) A population-based case-control study of endometrial cancer in shanghai, china. Int J Cancer 49:38-43. https://doi.org/10.1002/ijc.2910490108 
27. Lawrence C, Tessaro I, Durgerian S, et al (1987) Smoking, body weight, and early-stage endometrial cancer. Cancer 59:1665-1669. https://doi.org/10.1002/1097-0142(19870501)59:9<1665::AIDCNCR2820590924>3.0.C0;2-2

28. Sasco AJ, Ah-Song R, Gendre I, et al (1997) Endometrial cancer and tamoxifen. Discussion based on a case series. Bull Cancer 84:51-60

29. Narducci F, Lambaudie E, Sonoda Y, et al (2003) Controverses et nouveautés dans l'adénocarcinome de l'endomètre. Gynecol Obstet Fertil 31:581-596. https://doi.org/10.1016/S1297-9589(03)00173-5

30. Rep MK-CT, 1985 undefined Endometrial adenocarcinoma in breast cancer patients receiving antiestrogens. ci.nii.ac.jp

31. Fisher B, Costantino JP, Redmond CK, et al (1994) Endometrial cancer in tamoxifen-treated breast cancer patients: Findings from the national surgical adjuvant breast and bowel project (NSABP) B14. J Natl Cancer Inst 86:527-537. https://doi.org/10.1093/jnci/86.7.527

32. Trentham-Dietz A, Nichols HB, Hampton JM, Newcomb PA (2006) Weight change and risk of endometrial cancer. Int J Epidemiol 35:151-158. https://doi.org/10.1093/ije/dyi226

33. Burbos N, Musonda P, Duncan TJ, et al (2011) Estimating the Risk of Endometrial Cancer in Symptomatic Postmenopausal Women: A Novel Clinical Prediction Model Based on Patients' Characteristics. Int J Gynecol Cancer 21:500-506. https://doi.org/10.1097/IGC.0b013e31820c4cd6

34. Parazzini F, La Vecchia C, Moroni S, et al (1994) Family history and the risk of endometrial cancer. Int J Cancer 59:460-462. https://doi.org/10.1002/ijc.2910590404

35. Lucenteforte E, Talamini R, Montella M, et al (2009) Family history of cancer and the risk of endometrial cancer. Eur J Cancer Prev 18:95-99. https://doi.org/10.1097/CEJ.0b013e328305a0c9

36. Lécuru F, Ansquer Y, Bats AS, et al (2008) Cancer de l'endomètre du syndrome HNPCC. Actualisation des données. J. Gynecol. Obstet. Biol. la Reprod. 37:547-553

37. Zhou B, Yang L, Sun Q, et al (2008) Cigarette Smoking and the Risk of Endometrial Cancer: A MetaAnalysis. Am J Med 121:. https://doi.org/10.1016/j.amjmed.2008.01.044

38. Terry P, Baron JA, Weiderpass E, et al (1999) Lifestyle and endometrial cancer risk: A cohort study from the Swedish twin registry. Int J Cancer 82:38-42. https://doi.org/10.1002/(SICl)10970215(19990702)82:1<38::AID-IJC8>3.0.CO;2-Q

39. Levi F, La Vecchia C, Negri E, Franceschi S (1993) Selected physical activities and the risk of endometrial cancer. Br J Cancer 67:846-851. https://doi.org/10.1038/bjc.1993.155

40. Baekelandt MM, Castiglione M (2009) Endometrial carcinoma: ESMO Clinical Recommendations for diagnosis, treatment and follow-up. Ann Oncol 20:29-31. https://doi.org/10.1093/annonc/mdp120

41. Malik R, Agarwal R, Tandon $P$ (2008) Cytological assessment of endometrial washings obtained with an insemination cannula and its histological correlation. J Cytol 25:128. https://doi.org/10.4103/0970-9371.50797

42. Hemalatha AN, Pai MR, Raghuveer C V. (2006) Endometrial aspiration cytology in dysfunctional uterine bleeding. Indian J Pathol Microbiol 49:214-217 
43. Groff B, Pouget O, Stoll F, et al (2014) Pertinence du bilan préoperatoire dans l'évaluation du risque de métastases ganglionnaires d'un cancer endométrial. Gynecol Obstet Fertil 42:92-96. https://doi.org/10.1016/j.gyobfe.2013.08.003

44. Guo Q, Zhang Q, Lu L, Xu Y (2020) Long noncoding RNA RUSC1-AS1 promotes tumorigenesis in cervical cancer by acting as a competing endogenous RNA of microRNA-744 and consequently increasing Bcl-2 expression. Cell Cycle 19:1222-1235. https://doi.org/10.1080/15384101.2020.1749468

45. Rossard L, Rua C, Duquesne M, et al (2013) Pertinence de l'imagerie dans l'évaluation préopé ratoire des patientes avec cancer endométrial. Gynecol Obstet Fertil 41:641-647. https://doi.org/10.1016/j.gyobfe.2013.08.014

46. Nouni K, Iraqi M, Kebdani T, et al (2010) Traitements adjuvants et rôle de la radiothérapie dans le cancer de l'endomètre. Cancer/Radiothérapie 14:656. https://doi.org/10.1016/j.canrad.2010.07.609

47. Low EL, Simon AE, Waller J, et al (2013) Experience of symptoms indicative of gynaecological cancers in UK women. Br J Cancer 109:882-887. https://doi.org/10.1038/bjc.2013.412

48. Zarbo G, Caruso G, Caruso S, et al (2000) Endometrial cancer: Preoperative evaluation of myometrial infiltration magnetic resonance imaging versus transvaginal ultrasonography. Eur $\mathrm{J}$ Gynaecol Oncol 21:95-97

49. DelMaschio A, Vanzulli A, Sironi S, et al (1993) Estimating the depth of myometrial involvement by endometrial carcinoma: Efficacy of transvaginal sonography vs MR imaging. Am J Roentgenol 160:533-538. https://doi.org/10.2214/ajr.160.3.8430547

50. Kinkel K, Kaji Y, Yu KK, et al (1999) Radiologic staging in patients with endometrial cancer: A metaanalysis. Radiology 212:711-718. https://doi.org/10.1148/radiology.212.3.r99au29711

51. Taylor PJ, Hamou JE (1983) Hysteroscopy. J Reprod Med Obstet Gynecol 28:359-389. https://doi.org/10.1016/s0002-9378(36)80005-2

52. Chi DS, Welshinger M, Venkatraman ES, Barakat RR (1997) The role of surgical cytoreduction in Stage IV endometrial carcinoma. Gynecol Oncol 67:56-60. https://doi.org/10.1006/gyno.1997.4838

53. Chambers JT, Chambers SK (1992) Endometrial sampling: When? Where? Why? With what? In: Clinical Obstetrics and Gynecology. Clin Obstet Gynecol, pp 28-39

54. Yamashita Y, Mizutani H, Torashima M, et al (1993) Assessment of myometrial invasion by endometrial carcinoma: Transvaginal sonography vs contrast-enhanced MR imaging. Am J Roentgenol 161:595-599. https://doi.org/10.2214/ajr.161.3.8352114

55. Yazbeck C, Poncelet $C$, Créquat J, Madelenat $P$ (2003) Intérêt de l'échographie endovaginale préopératoire dans l'évaluation de l'infiltration myométriale des adénocarcinomes de l'endomètre. Gynecol Obstet Fertil 31:1024-1029. https://doi.org/10.1016/j.gyobfe.2003.07.008

56. Grahek D, Barranger E, Daraï E, et al (2005) Intérêt de la tomographie par émission de positons au [18F]-fluorodésoxyglucose dans le diagnostic, le bilan d'extension et la recherche de récidive des cancers gynécologiques et mammaires. Gynécologie Obs Fertil 33:371-381. https://doi.org/10.1016/j.gyobfe.2005.01.005 
57. Brémond A, Bataillard A, Thomas L, et al (2001) Standards, options et recommandations pour la prise en charge chirurgicale des patientes atteintes de cancer de l'endomètre. Bull. Cancer 88:181198

58. Hoekstra A V., Morgan JM, Lurain JR, et al (2009) Robotic surgery in gynecologic oncology: Impact on fellowship training. Gynecol Oncol 114:168-172. https://doi.org/10.1016/j.ygyno.2009.04.022

59. H K, AM S, Q Q, et al (2009) Efficacy of systematic pelvic lymphadenectomy in endometrial cancer (MRC ASTEC trial): a randomised study. Lancet 373:125-136. https://doi.org/10.1016/S01406736(08)61766-3

60. Kong A, Johnson N, Kitchener HC, Lawrie TA (2012) Adjuvant radiotherapy for stage i endometrial cancer: An updated cochrane systematic review and meta-analysis. J. Natl. Cancer Inst. 104:16251634

61. Colombo N, Creutzberg C, Amant F, et al (2016) ESMO-ESGO-ESTRO consensus conference on endometrial cancer: Diagnosis, treatment and follow-up. Ann Oncol 27:16-41. https://doi.org/10.1093/annonc/mdv484

62. Morrow CP, Bundy BN, Kurman RJ, et al (1991) Relationship between surgical-pathological risk factors and outcome in clinical stage I and II carcinoma of the endometrium: A gynecologic oncology group study. Gynecol Oncol 40:55-65. https://doi.org/10.1016/0090-8258(91)90086-K

63. Nelson G, Randall M, Sutton G, et al (1999) FIGO stage IIIC endometrial carcinoma with metastases confined to pelvic lymph nodes: Analysis of treatment outcomes, prognostic variables, and failure patterns following adjuvant radiation therapy. Gynecol Oncol 75:211-214. https://doi.org/10.1006/gyno.1999.5569

64. Seski JC, Edwards CL, Herson J, Rutledge FN (1982) Cisplatin chemotherapy for disseminated endometrial cancer. Obstet Gynecol 59:225-228

65. de Boer SM, Powell ME, Mileshkin L, et al (2016) Toxicity and quality of life after adjuvant chemoradiotherapy versus radiotherapy alone for women with high-risk endometrial cancer (PORTEC-3): an open-label, multicentre, randomised, phase 3 trial. Lancet Oncol 17:1114-1126. https://doi.org/10.1016/S1470-2045(16)30120-6

66. Steer $C$, Harper $P$ (2001) Is there any place for cytotoxic chemotherapy in endometrial cancer? Best Pract Res Clin Obstet Gynaecol 15:447-467. https://doi.org/10.1053/beog.2001.0188

67. Lim P, Aquino-Parsons CF, Wong F, et al (1999) Low-risk endometrial carcinoma: Assessment of a treatment policy based on tumor ploidy and identification of additional prognostic indicators. Gynecol Oncol 73:191-195. https://doi.org/10.1006/gyno.1999.5365

\section{Tables}

Table 1. Repartition of patients according to race. 


\begin{tabular}{|lll|}
\hline Race & $\mathbf{N}$ & $\%$ \\
White & $\mathbf{7 8}$ & $\mathbf{8 3 . 8 8}$ \\
Arab & 64 & 68.8 \\
Amazigh & 14 & 15 \\
Black & $\mathbf{1 2}$ & $\mathbf{1 2 . 9}$ \\
Arab & 12 & 12.9 \\
Amazigh & 0 & 0 \\
Métis & $\mathbf{3}$ & $\mathbf{3 . 2 2}$ \\
Arab & 0 & 0 \\
Amazigh & 3 & 3.22 \\
\hline
\end{tabular}

Table 2. Hormonal risk Factors of endometrial cancer

\begin{tabular}{|lll|}
\hline Hormonal Factors & N & (\%) \\
\hline Early Menarche (<12 years) & 34 & 36.5 \\
\hline Menstrual Cycle Abnormality (Long or irregular) & 16 & 17.2 \\
\hline Parity & & \\
Nulliparous & 38 & 40.8 \\
Pauciparous ( $\leq 2$ Children) & 45 & 48.38 \\
Multiparous (> 2 Children) & 10 & 10.75 \\
\hline hormonal Contraception & 43 & 46.2 \\
\hline Late Menopause & 14 & 15 \\
\hline Medical Hormonal Treatment & 3 & 3.2 \\
\hline Tamoxifen & 9 & 9.6 \\
\hline
\end{tabular}

Tableau 3. Repartition of patients according to others comorbidities. 


\begin{tabular}{|lll|}
\hline Comorbidities & N & (\%) \\
\hline Diabetes & 58 & 62.3 \\
Type I & 7 & 7.5 \\
Type II & 51 & 54.8 \\
\hline Cholesterol $>$ 2g/L & 45 & 48.3 \\
\hline Obesity & 74 & 79.5 \\
$25<$ BMI $<30$ & 42 & 45.1 \\
BMl $>30$ & 32 & 34.4 \\
\hline HBP & 46 & 49.4 \\
\hline Abdominal Perimeter $>100 \mathrm{~cm}$ & 71 & 76.3 \\
\hline
\end{tabular}

HBP: High Blood Pressure

Tableau 4. Histopathological Characteristics of endometrial tumors. 


\begin{tabular}{|c|c|c|}
\hline Characteristic & $\mathbf{N}$ & $\%$ \\
\hline \multicolumn{3}{|c|}{ FIGO Stage (2018) } \\
\hline IA & 41 & 44.08 \\
\hline IB & 11 & 11.82 \\
\hline ॥ & 9 & 9.67 \\
\hline III & 17 & 18.27 \\
\hline IV & 15 & 16.12 \\
\hline \multicolumn{3}{|l|}{ histological Type } \\
\hline Endometrioid & 76 & 81.72 \\
\hline Serous & 11 & 11.82 \\
\hline Clear Cells & 3 & 3.22 \\
\hline Undifferentiated & 1 & 1.07 \\
\hline Carcinosarcoma & 2 & 2.14 \\
\hline \multicolumn{3}{|c|}{ Histogenetic Type } \\
\hline Type 1 & 76 & 81.72 \\
\hline Type 2 & 17 & 18.27 \\
\hline \multicolumn{3}{|c|}{ Histological Grade } \\
\hline G1 & 48 & 51.61 \\
\hline G2 & 21 & 22.58 \\
\hline G3 & 24 & 25.8 \\
\hline \multicolumn{3}{|c|}{ Macroscopic Size } \\
\hline$<20 \mathrm{~mm}$ & 37 & 39.78 \\
\hline$\geq 20 \mathrm{~mm}$ & 56 & 60.21 \\
\hline \multicolumn{3}{|c|}{ Myometrial Invasion } \\
\hline Absence & 29 & 31.18 \\
\hline$<50 \%$ & 11 & 11.82 \\
\hline$\geq 50 \%$ & 53 & 56.98 \\
\hline \multicolumn{3}{|l|}{ Depth of invasion } \\
\hline$\geq 3 \mathrm{~mm}$ & 64 & 68.81 \\
\hline$<3 \mathrm{~mm}$ & 29 & 31.18 \\
\hline
\end{tabular}




\begin{tabular}{|lcc|} 
Cervical Extension & & \\
Yes & 9 & 9.67 \\
No & 84 & 90.32 \\
\hline Vascular emboli & & \\
Yes & 21 & 22.58 \\
No & 72 & 77.42 \\
\hline Lymph Node Invasion & & \\
Yes & 15 & 16.13 \\
No & 37 & 39.78 \\
NP* & 41 & 43.91 \\
\hline Extra-uterus Extension & & \\
Yes & 15 & 16.13 \\
No & 78 & 83.87 \\
\hline
\end{tabular}

*NP: Not performed (no indication for dissection: stage IA, G1 and G2 or non-optimal surgery $(R=1)$ ) Table 5. Clinical signs of endometrial cancers.

\begin{tabular}{|lll|}
\hline clinical Signs & N & $\%$ \\
\hline Metrorrhagias & 68 & 62,2 \\
\hline Pelvic pain & 27 & 29 \\
\hline Leucorrhea & 11 & 11.8 \\
\hline Urinary Signs & 8 & 8,6 \\
\hline Digestive Signs & 7 & 7.7 \\
\hline Alteration of the general condition & 5 & 5.37 \\
\hline
\end{tabular}

Figures 


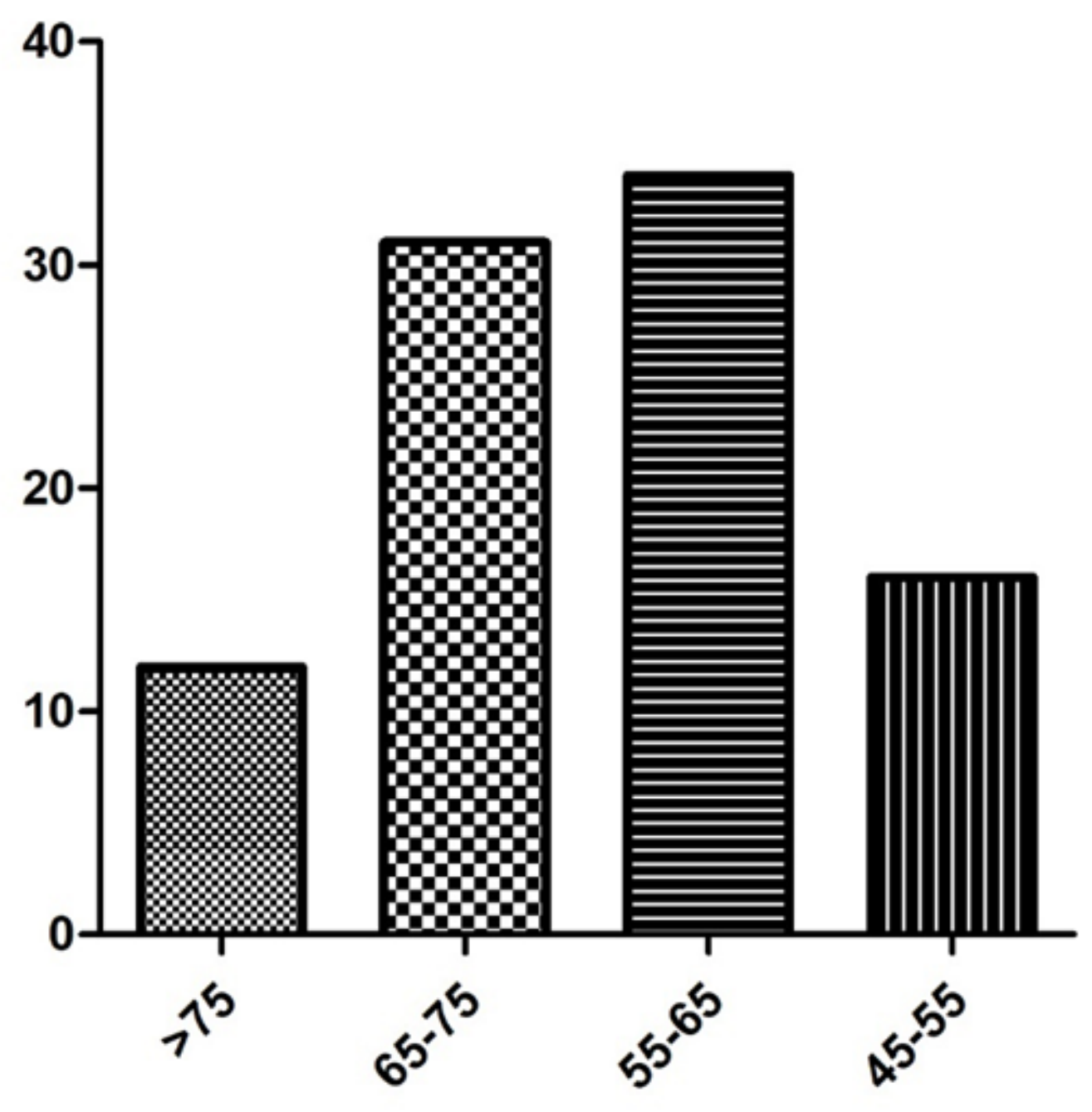

Figure 1

Global distribution of endometrial cancer according to age.
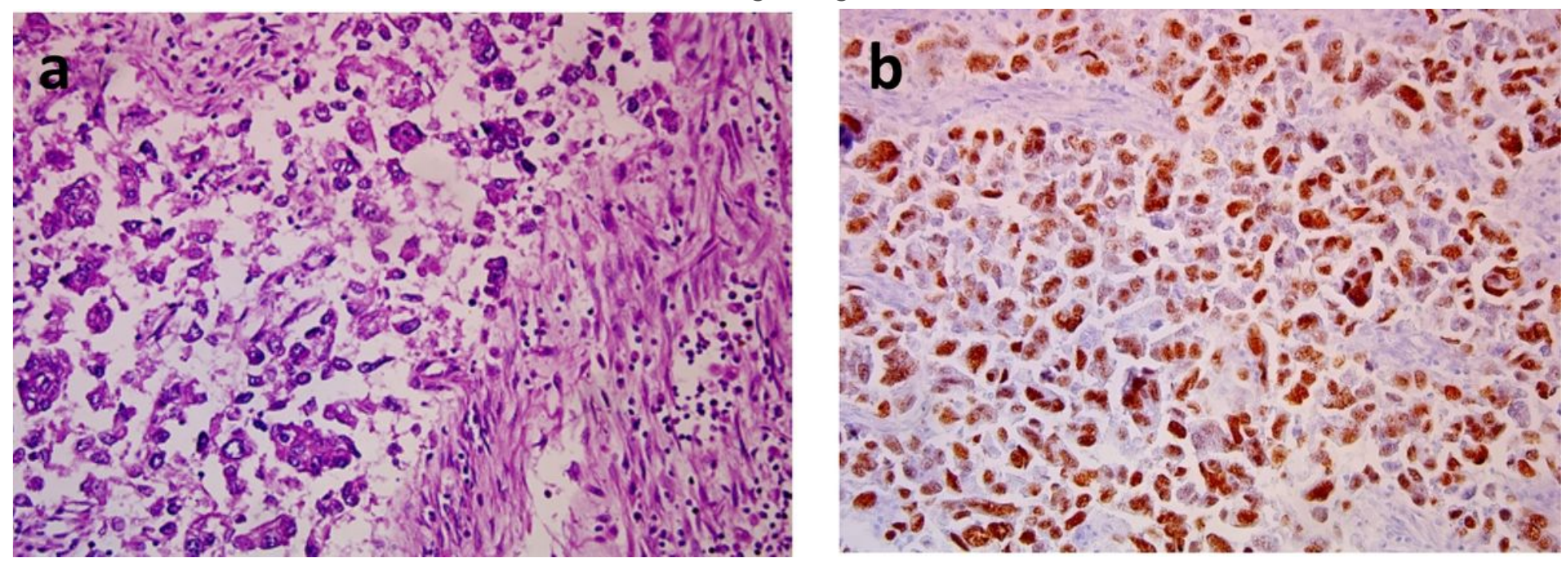

Figure 2 
54-year-old patient. a) Endometrial clear cell ADK. b) Immunohistochemistry: P53 positive

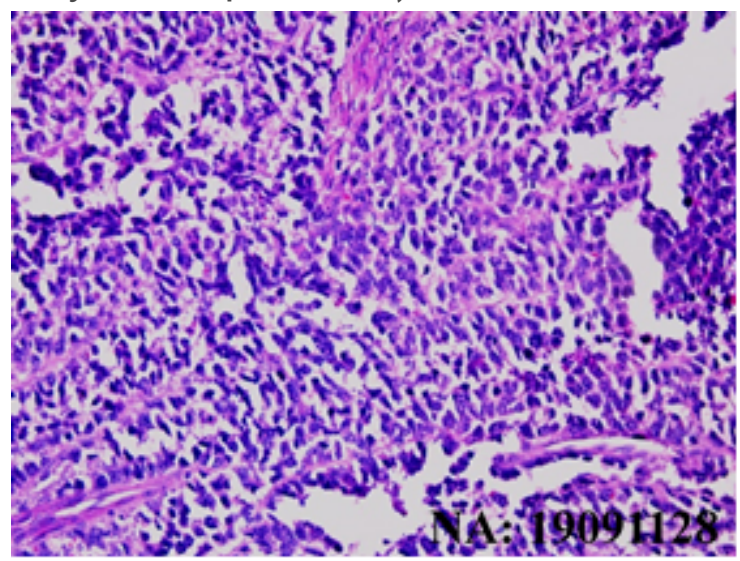

Figure 3

72-year-old patient. Well differentiated endometrioid ADK

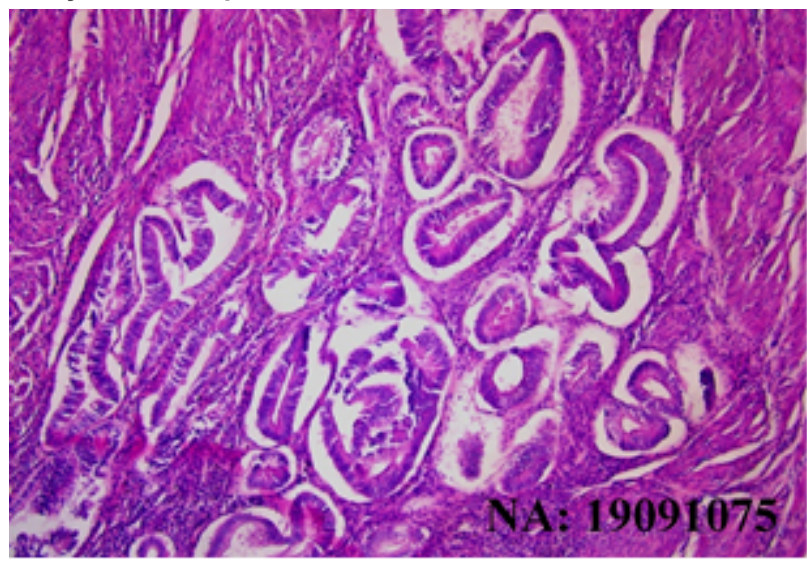

Figure 4

61-year-old patient. Poorly differentiated endometrioid ADK 


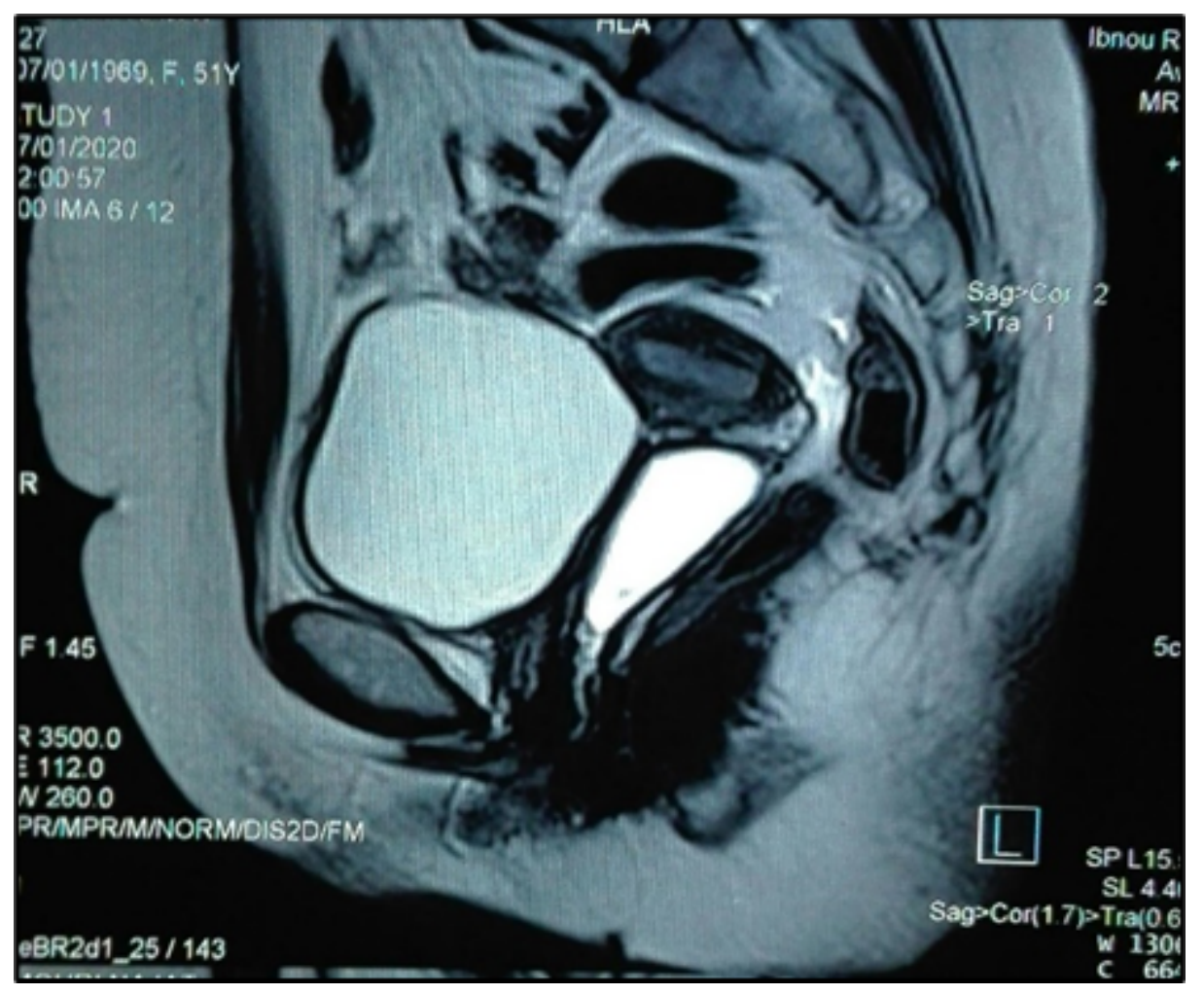

Figure 5

Pelvic MRI objectifying a regular endometrial thickening measuring $27 \times 10.6 \mathrm{~mm}$ with an infiltration of the myometrium $\otimes 50 \%$ and right external iliac lymphadenopathy, the largest of which is $12 \mathrm{~mm}$ short axis 


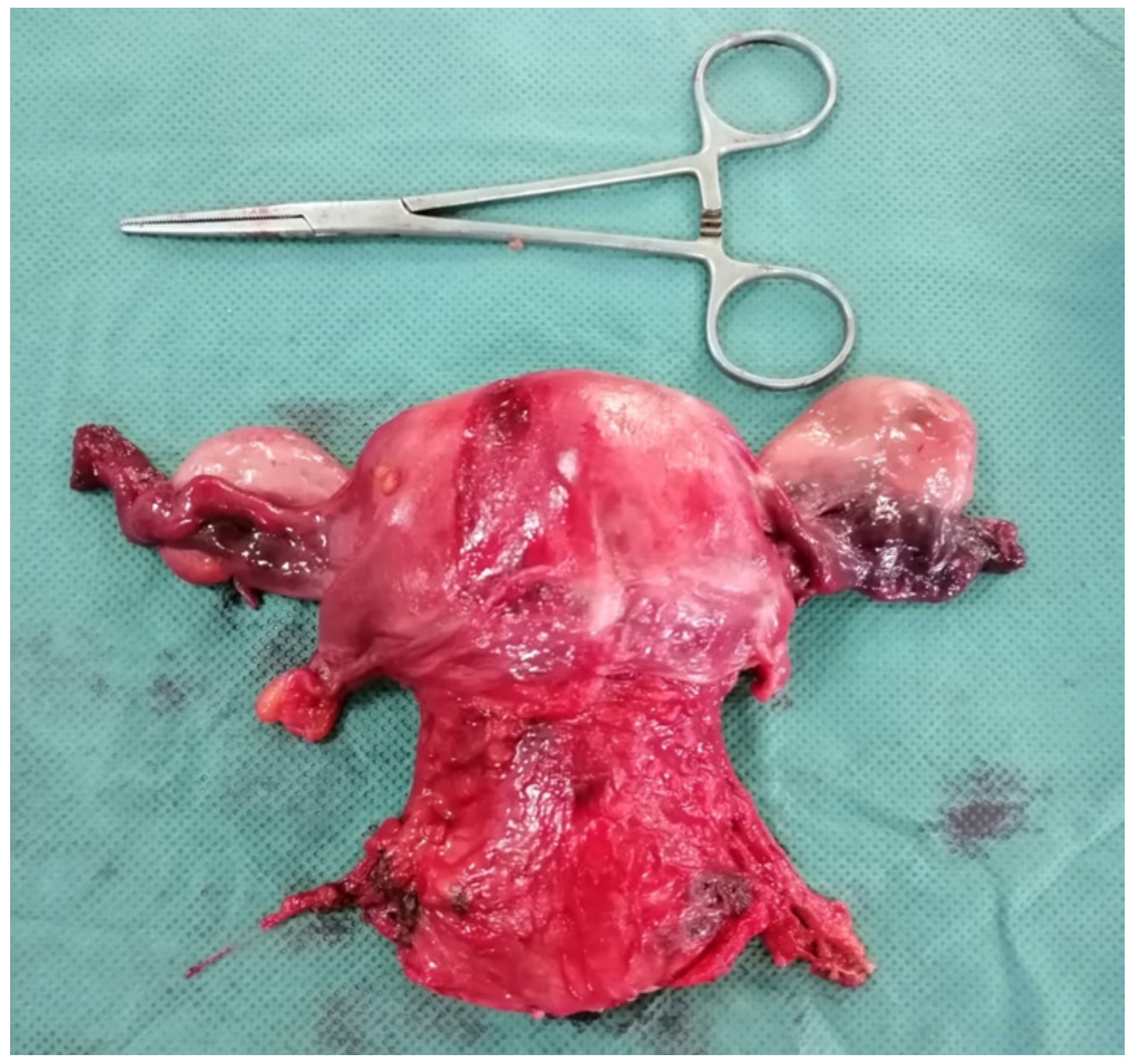

\section{Figure 6}

61-year-old patient. endometroid ADK with extension to the uterine cervix. Specimen of an enlarged colpohysterectomy. 


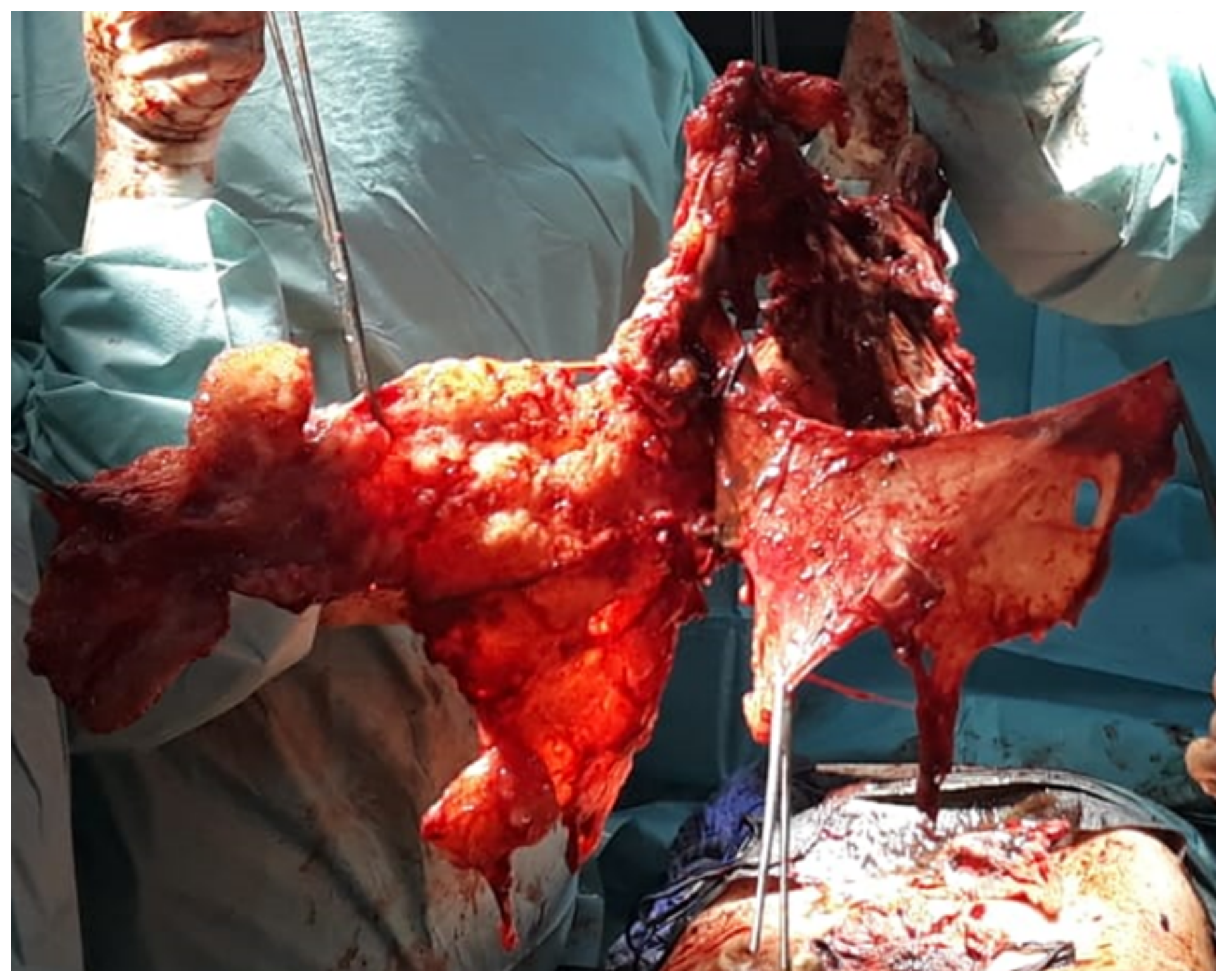

Figure 7

64-year-old patient. Endometrial carcinosarcoma. Hysterectomy specimen, omentectomy, peritonectomy and small bowel resection. 